\title{
Technology-Based Newborn Health Learning Initiatives for Facility-Based Nurses and Midwives in Low- and Middle-Income Countries: A Scoping Review
}

\author{
Nancy E. Bolan, $\odot$ Susan D. Newman, and Lynne S. Nemeth
}

PURPOSE: Given high neonatal mortality in many low- and middle-income countries, addressing missed opportunities by enhancing the quality of newborn care provided by facility-based nurses and midwives is critical. This scoping review synthesizes and critiques the literature on technology-based newborn health learning initiatives. Kirkpatrick's model is used for training program evaluation.

METHODS: A literature review was conducted from multiple databases. Articles selected for analysis consisted of original research studies published in peer-reviewed journals from 2012 to 2017.

RESULTS: Twelve studies fell into two categories: (a) Simulation training in routine neonatal care and newborn resuscitation $(n=9)$ and (b) eLearning initiatives $(n=3)$. Most studies evaluated health provider's knowledge and skills before and/or after training $(n=9)$; fewer evaluated the effect on change in provider practice $(n=3)$ and/or patient health outcomes $(n=5)$ (Kirkpatrick levels $3-4)$. Few studies utilized robust study designs and validated measurement instruments.

CONCLUSION: Learning approaches emphasizing simulation training and eLearning initiatives for facility-based health workers hold promise. However, existing simulation literature demonstrates that translation of knowledge gained during simulation into improved clinical outcomes in real births is variable. Additionally, the volume of peer-reviewed evidence demonstrating the potential benefit of eLearning strategies, especially in the neonatal period, is limited.

KEYWORDS: nurses; midwives; newborn; neonatal; training; technology

\section{BACKGROUND}

It has been argued that the greatest test of health system function is the ability to provide timely care at birth (World Health Organization [WHO], 2005). The reality is that worldwide, of the 140 million babies born each year (WHO, 2017), almost one million newborns die on their first day of life, and close to one million die during their first week of life (United Nations Children's Fund [UNICEF], 2017). An additional one million of the surviving infants develop neurocognitive problems such as cerebral palsy and learning difficulties (Ersdal \& Singhal, 2013). ${ }^{1}$ An estimated $99 \%$ of these deaths occur in low-and middleincome countries. Although some regions have made progress in decreasing neonatal mortality, the highest mortality regions have seen insufficient progress in the last decade. "Early neonatal deaths" are those that occur in the first week of life, while "perinatal deaths" are comprised of early neonatal deaths and intrapartum ("fresh") stillbirths; "neonatal deaths" are those deaths occurring in the first 28 days of life (Lawn, Lee, et al., 2009). As post-neonatal mortality (in children under 5 years of age) has decreased 
dramatically over the past 15 years globally, there has been slower progress in reducing the neonatal mortality rate, with neonatal deaths accounting for an increasing proportion of under-5 mortality. In fact, the share of neonatal deaths is projected to increase from $47 \%$ of under-five deaths in 2015 to $52 \%$ in 2030 (UNICEF, 2017). The three major causes of neonatal deaths are preterm birth complications, intrapartum-related "birth asphyxia," and infections, which account for more than $85 \%$ of newborn deaths (Tuncalp et al., 2015).

The time of greatest risk of mortality and morbidity for both the mother and baby is at birth, when a large percentage of the newborn deaths occur (UNICEF, 2018). Intrapartum-related neonatal deaths, formerly referred to as "birth asphyxia" (i.e., failure to initiate spontaneous respirations and/or 5 min Apgar score of less than 7), are closely linked with maternal complications and death (Lawn, Lee, et al., 2009). ${ }^{2}$ In reality, the vast majority of neonatal deaths can be prevented or treated by relatively straightforward, effective interventions practiced by health workers starting with primary prevention such as skilled attendance at birth and early recognition and timely management of obstetric complications (Chandrasekaran, Thukral, \& Deorari, 2014; UNICEF, 2017). Secondary prevention focuses largely on early neonatal care and neonatal resuscitation, while tertiary prevention centers on management of the baby with complications (Lawn, Lee et al., 2009; Ersdal \& Singhal, 2013).

The WHO estimates that while $5 \%-10 \%$ of newborns worldwide do not breathe immediately at birth and require some level of assistance to initiate respirations, $3 \%-6 \%$ require basic neonatal resuscitation consisting of simple initial steps and assisted ventilation via bag-mask or face-mask ventilation (WHO, 1998). Less than $0.1 \%$ of neonates require advanced resuscitation techniques such as chest compressions and vasoactive medications (Wall et al., 2009). Simple immediate newborn care includes warming, drying, stimulation, hygiene and thermal care. Providing these immediate steps to newborns in all settings is known as essential newborn care, and can even be performed by family members or community members in births at home (Wall et al., 2009). Basic neonatal resuscitation training can be effectively performed by a wide range of health providers, resulting in reductions in intrapartum-related mortality (Lawn, Kinney, et al., 2009). Evidence from several observational studies show that facility-based basic neonatal resuscitation alone may avert $30 \%$ of intrapartum-related neonatal deaths in full-term babies, plus $5 \%-10 \%$ in preterm babies (Lawn, Kinney, et al., 2009; Wall et al., 2009).
Despite an increased global emphasis on institutional births, for the estimated 44 million women who give birth annually without skilled care at birth, mostly at home, there is an inverse relationship between access to skilled care at birth and intrapartum-related neonatal mortality (Lawn et al., 2017; Prakash et al., 2016). The coverage gap of skilled birth attendance is widest in certain regions, namely sub-Saharan Africa and South Asia, where baseline coverage is lowest globally (Lawn, Lee et al., 2009However, the place of birth has changed in the last two decades. More than $80 \%$ of all births globally now occur with a skilled birth attendant. Although globally in 2016 three in every four live births were attended by a skilled health provider, increases in coverage of facility delivery and skilled attendance at birth have resulted in only limited reductions in maternal and neonatal deaths. This incongruous finding is believed to relate to the inadequate level of care that many women and children receive in health facilities (Marchant et al., 2015). There is, however, still more variability in community settings that pose challenges to effective and sustainable program implementation and scale-up as compared with facility-based settings (Wall et al., 2009).

One key impediment in low- and middle-income countries is clearly the gap in quality coverage and the lack of skilled birth attendants and newborn care providers proficient in essential newborn care and neonatal resuscitation (Ersdal \& Singhal, 2013; Wall et al., 2009). Neonatal resuscitation is one of the "signal functions" of emergency obstetric and newborn care (EmONC) that must be provided by all skilled birth attendants (Lund et al., 2016). In reality, low knowledge and confidence in neonatal resuscitation among neonatal providers has been documented, and lack of initial, refresher training has been identified as a key contributor (Rule et al., 2017; Subbiah, Sarin, Jeeva, \& Geetanjali, 2012). For babies born in hospitals in South Asia and sub-Saharan Africa, staff often lack training in resuscitation and equipment is not available. Assessments in six African countries showed only $2 \%$ to $12 \%$ of personnel conducting births in facilities had been trained in neonatal resuscitation, and only $8 \%$ to $22 \%$ of facilities had equipment for newborn respiratory support. A key challenge is how to seize the missed opportunity to ensure adequate provision of essential newborn care and basic resuscitation for births already occurring in facility settings, including equipment and competent personnel (Wall et al., 2009). Key constraints include cost, availability of competent trainers, and the rapid pace of updates to information, technology, and 
clinical recommendations (Chandrasekaran et al., 2014; Klunklin, Viseskul, Sripusanapan, \& Turale, 2010).

Nurses and midwives are crucial to strengthening health systems and achieving improved maternal and child health (Bell, Rominski, Bam, Donkor, \& Lori, 2013; WHO, 2011a). However, particularly in rural areas where there is the lowest coverage of skilled care at birth and neonatal mortality is highest, access to relevant up-to-date learning opportunities is difficult or impossible to obtain (Hudspeth, Curry, Sacks, \& Surena, 2015; WHO, 2006). Given the challenges of organizing learning opportunities for health workers in remote settings, expanding mobile phone penetration holds promise for new technological mechanisms to reach these health workers with up-to-date information (Nilsson, Sorensen, \& Sorensen, 2014); however, published robust research on newborn health learning initiatives using technology is limited (Amoakoh et al., 2017; Chandrasekaran et al., 2014).

The purpose of this scoping review was to explore what is known from the existing research literature about technology-based newborn health learning initiatives for health workers in low- and middle-income countries, with an emphasis on nurses and midwives. Kirkpatrick's model for the evaluation of training programs (Kirkpatrick, 1996) was used as the guiding framework to consider the various learning initiatives.

\section{METHODS}

\section{Approach}

The approach applied in this Scoping Review utilized a five-stage process as outlined by Arksey and O'Malley (2005): (a) identifying the research question, (b) identifying relevant studies, (c) study selection, (d) charting the data, and (e) collating, summarizing, and reporting the results.

\section{Search Strategy}

The author searched the electronic, academic peerreviewed journals for studies published over the last 5 years, from 2012 to 2017, in order to limit findings to more recent papers. Multiple electronic databases were searched including PubMed, EBSCO host platform (including Cumulative Index of Nursing and Allied
Health Literature [CINAHL], Medline, ERIC, Education Full text and PsycINFO), and Scopus. Key search terms were (a) nurse(s), nursing, midwifery, midwife(s); (b) training, education, learning, continuing education, professional development, performance support; (c) maternal health, newborn health, neonate, neonatal;

(d) technology, eHealth, mHealth, digital health, mobile phones, computers, electronic, simulation; and (e) lowincome countries, developing countries, low-resource countries, Asia, and Africa. Bibliographies of included papers were also manually searched.

\section{Inclusion/Exclusion Criteria}

Articles were included in this review if they addressed nurses', midwives', or other health workers' technologybased training or learning interventions, in a low- or middle-income country, targeting the clinical provision of newborn care. Studies were excluded that focused on research protocols, multi-intervention quality improvement projects, descriptions of undergraduate curricula, and studies on training of traditional birth attendants or community health workers only. Studies were also excluded if the full texts were not available. Editorials, opinions, and reviews were excluded.

\section{Data Evaluation and Analysis}

The database search identified 576 papers. Duplicates were removed and papers were screened by title and abstract, leaving 36 papers. After full-text review, 27 papers were excluded and nine studies remained. An additional three studies were identified through bibliographic ancestry review, leaving 12 studies for analysis in the final review. Search results are found on the accompanying PRISMA diagram (Figure 1). Kirkpatrick's Model was used to assess training program evaluation in the interventions reviewed (Kirkpatrick, 1996) (Table 1). Kirkpatrick considers evaluation of training programs across four levels: (a) Reaction (evaluates how participants assess the training); (b) Learning (measures if participants acquired knowledge, learned skills, or changed attitudes), (c) Behavior (considers if they are using what they learned at the training on the job), and (d) Results (evaluates if the training positively impacted organization and/or patient outcomes). Kirkpatrick noted that training evaluation becomes more meaningful as it progresses from level 1 to 4 , but that ideally all four levels of any training should be evaluated. 


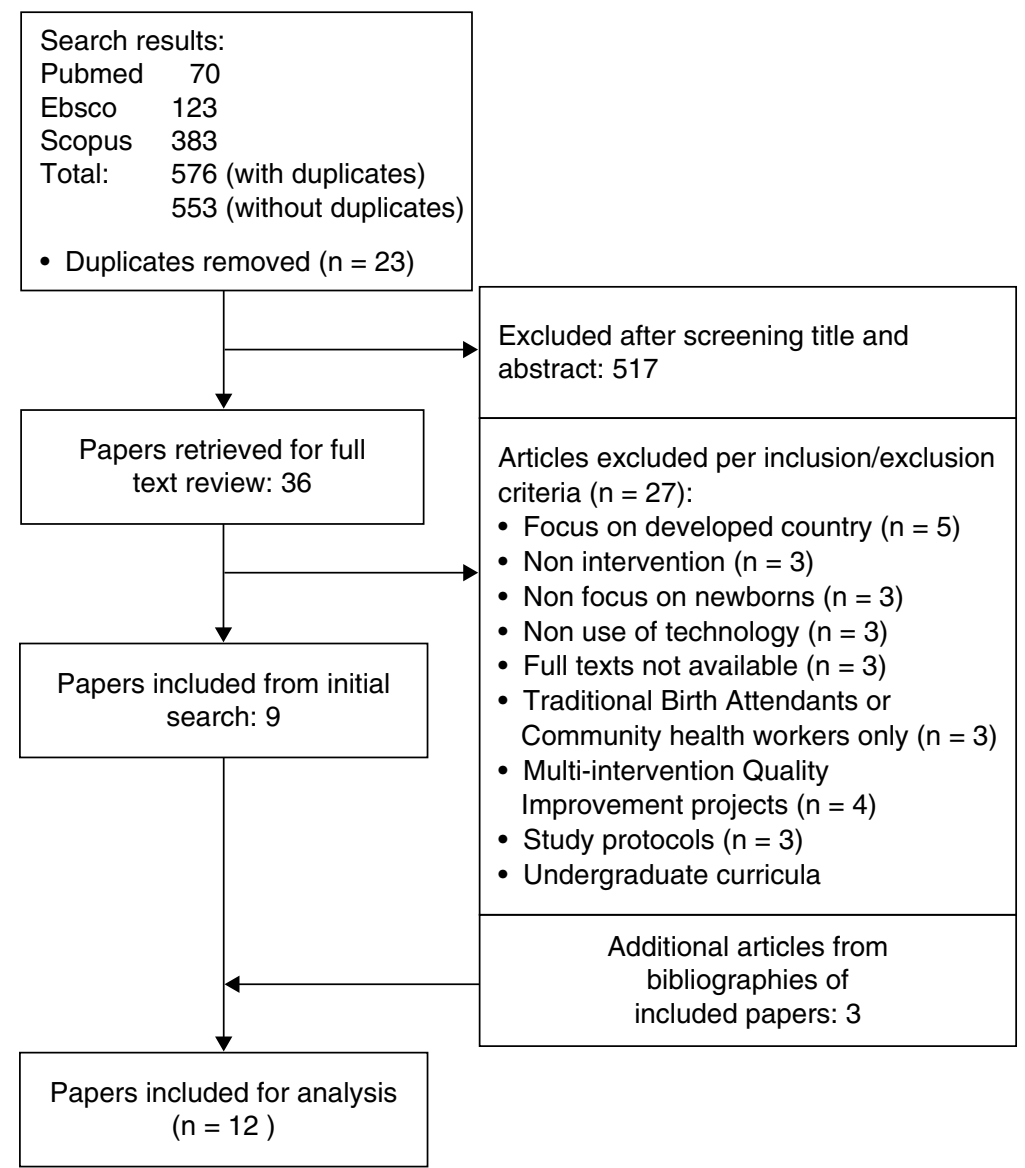

FIGURE 1. PRIMSA flow diagram.

TABLE 1. Kirkpatrick Levels Measured in Included Articles

\section{FIRST AUTHOR, MEASURES} YEAR

Simulation training with HBB $(n=6)$ and other training methodologies $(n=3)$

Subbiah et al. (2012) Knowledge and Skills: Structured knowledge questionnaire on NR. Observational checklist on routine care and NR.

Goudar et al. (2012) Results: 24-hour, 7-day, and 28-day neonatal outcomes.

2: Learning

Msemo et al. (2013) Behavior: Use of stimulation, suctioning and FMV was monitored in pre- and post-

Ersdal et al. (2013) Skills: Two simulation scenarios, "routine care" and "neonatal resuscitation," were HBB intervention births.

Results: Primary outcomes were a reduction in ENM within 24 hours and rates of FSBs. performed by 39 providers, 7 months before (September 2009), and 27 providers, 7 months after (November 2010) HBB training in April of 2010. Two independent raters scored the videotaped scenarios for "pass/fail" performance and different skills.

Behavior: Observational data was collected in the delivery room during 7 months pre $(n=2,745)$ and 7 months post $(n=3,116)$ HBB training (April 2010) by

4: Results

3. Behavior

4: Results

2: Learning (Skills) observing all hospital births during the same period. 
TABLE 1. Kirkpatrick Levels Measured in Included Articles (Continued)

\section{FIRST AUTHOR, MEASURES YEAR}

Seto et al. (2015)

Bang et al. (2016)

Bellad et al. (2016)

Eblovi et al. (2017)

Prakash et al. (2016)
Reaction to training: Pre- and post confidence levels, post-HBB course satisfaction.

Knowledge and Skills test: MCQs pre- and post for NR knowledge. Bag-mask ventilation skills checklist (a seven-item checklist of skills to perform effective ventilation) and two OSCEs ( $\mathrm{A}$ - one for routine newborn care) (B - one complex resuscitation scenario).

Knowledge and Skills: Compared pass rates for skills and knowledge pre- and post-initial HBB training and following refresher training among birth attendants. OSCE B tested resuscitation skill retention by comparing post-initial training performance with pre-refresher training performance.

Results: Comparison of pre- and post-HBB training of FSR, numbers of FSBs and 7-day neonatal mortality rate giving composite PMR, among all live registry births in study clusters and registry births in HBB-trained facilities.

Skills: Trainee skills were evaluated by OSCE at three time points: immediately, 4 months after HBB training, and 4 months after the refresher training.

Behavior: Midwives recorded in logbooks the highest level of NR performed on all newborns delivered for 1 year.

Results: The mortality rate in the first 24 hours of life reported by midwives during the 1-year study was compared with nationwide estimates of first 24-hour mortality in Ghana from 2007 to 2013.

Skills test: Skills evaluated by clinical complexity of the simulated scenario, ranging from level 1, requiring NR without a maternal complication, to level 3, requiring simultaneous management of neonatal and maternal complications. Simulations videorecorded and coded for predefined clinical skills using "Studiocode."

\section{eHealth/eLearning interventions $(n=3)$}

Thukral et al. (2012) Reaction: Participant satisfaction evaluated on a 5-point Likert scale Knowledge and Skills: Knowledge and skill changes were evaluated by administering online MCQs and on-site OSCE stations before and after completion of the course on essential newborn care.

\section{Reaction: Participant satisfaction evaluated on a 5-point Likert scale}

Knowledge and Skills: Knowledge and skill changes were evaluated by administering online MCQs and on-site OSCE stations before and after completion of the course. Baseline knowledge and skill scores of pediatricians working in SNCUs in the state of Tamil Nadu, India ( $n=32$ ) were assessed by 25 MCQs and by five OSCE skill stations.

Knowledge and Skills: Knowledge and skills in NR were assessed at baseline and at 6 and 12 months after the intervention. Knowledge and skills assessed via questionnaire and objective structured assessment of technical skills using simulated scenarios with scoring on skills performance on mannequins.

Results: Perinatal mortality was defined as a composite of a stillbirth or an early neonatal death. Outcome was recorded at delivery.

\section{KIRKPATRICK LEVEL}

1: Reaction

2: Learning

2: Learning

4: Results

2: Learning

3. Behavior

4: Results

2: Learning

1: Reaction

2: Learning

1: Reaction

2: Learning

2: Learning

4: Results

Note. $\mathrm{NR}=$ neonatal resuscitation; FMV = face-mask ventilation; ENM = early neonatal mortality; FSB = fresh stillbirth; HBB = Helping Babies Breathe; $\mathrm{MCQs}$ $=$ multiple-choice test questions; $\mathrm{OSCE}=$ objective structured clinical evaluation; FSR $=$ fresh stillbirth rates; $\mathrm{PMR}=$ perinatal mortality rate; $\mathrm{SNCU}=$ special newborn care unit.

\section{RESULTS}

Twelve studies are included in this review. Studies were conducted in India $(n=5)$ (Goudar et al., 2012; Prakash et al., 2016; Subbiah et al., 2012; Thukral et al., 2012; Vail et al., 2017), sub-Saharan Africa $(n=4)$ (Eblovi et al., 2017; Ersdal et al., 2013; Lund et al., 2016; Msemo et al., 2013), both India and Africa $(n=2)$ (Bang et al., 2016; Bellad et al., 2016), and one study was conducted in Honduras (Seto et al., 2015). All twelve studies were published in English. Studies were all conducted using quantitative methods with the exception of one study that used mixed methods (Prakash et al., 2016). The 
studies collectively addressed all four of Kirkpatrick's training evaluation levels, and a number of the studies specifically noted the use of Kirkpatrick's model as part of their research approach. The majority of studies evaluated health provider knowledge and skills before and/or after training $(n=9)$; fewer studies evaluated the effect on change in provider practice $(n=3)$ and/or patient health outcomes $(n=5)$ (Kirkpatrick levels 3 and 4). Table 1 presents the consideration of the respective Kirkpatrick levels in the learning interventions' training evaluation methods. Only a few of the included studies utilized more robust study designs, such as randomized controlled trials (RCTs), and validated measurement instruments.
The interventions included in this review fall into two main categories (Tables 2 and 3): (a) Simulation training in routine neonatal care and neonatal resuscitation via Helping Babies Breathe (HBB) courses (American Academy of Pediatrics [AAP], n.d.-a) $(n=6)$ (Bang et al., 2016; Bellad et al., 2016; Eblovi et al., 2017; Ersdal et al., 2013; Msemo et al., 2013; Seto et al., 2015) and other training programs $(n=3)$ (Goudar et al., 2012; Subbiah et al., 2012; Vail et al., 2017) and (b) eHealth/ eLearning initiatives (defined as the use of information and communication technologies for health and learning, respectively) $(n=3)$ (Lund et al., 2016; Prakash et al., 2016; Thukral et al., 2012; WHO, 2011b). Tables 2 and 3 present the studies per these categories, respectively.

TABLE 2. Simulation Training With HBB $(n=6)$ and Other Methodologies $(n=3)$

CITATION STUDY DESIGN

Subbiah et al. Prospective intervention (2012) study, with one group preand post-, to assess the effectiveness of NR educational intervention modules developed by National Neonatology Forum, India.

Goudar et al. Study was part of a (2012)

Ersdal et al. (2013) mortality in rural India. multicountry prospective, community-based cluster $\mathrm{RCT}$, to evaluate the effect of WHO ENC course and the AAP NRP training on perinatal

Prospective intervention study, with one group preand post-, to (a) determine the effect on practical skills and clinical management 7 months after HBB training, and (b) describe neonatal management in the delivery room during the pre and post time period.

\section{PARTICIPANTS}

Nurses working in nursery,

labor room, postnatal ward of secondary and tertiary hospitals across the country. $n=71$ Setting: India

All women with pregnancies greater than 28 weeks. $n=25,096$ births in homes and hospital facilities Setting: 26 study communities in Karnataka, India

\section{INTERVENTION}

Five-day workshop on routine neonatal care and NR using lecture, discussions, and demonstrations followed by hands-on training using mannequins.

Mortality rates preand post-ENC training (for nurses, MDs, auxiliary nurse midwives, TBAs) were collected prospectively and then communities were randomized to either receive (NRP) training or refresher newborn care training in the control clusters. Trainings were 1-5 days.

Midwives, nurses, and ward attendants (assistants without any formal medical education). $n=39$ (pre) and 27 (post) Setting: Tanzania, in one rural hospital (see below sample in Msemo et al.)
A 1-day HBB training was conducted in April 2010. The course methodology focused on hands-on practice using a simulator mannequin, emphasizing the first basic steps: drying, stimulation, suction, warmth, and initiation of FMV within the "Golden Minute" after birth. $^{\text {a }}$

\section{KEY FINDINGS}

Knowledge and Skills: Mean difference in knowledge from pre to post was 11.6 out of $45(p<.001)$. Skills mean difference 7.8 out of $33(p<.05)$.

Results: Perinatal mortality for infants $\geq 500$ g decreased from 52 to 36/1,000 after ENC training (RR 0.7; 95\% $\mathrm{Cl} 0.5$, 0.9); mortality was not reduced further with NR training.

\section{Knowledge and Skills:} Providers who "passed" the simulated "routine care" and "NR" scenarios increased from 41 to $74 \%$ ( $p=.016)$ and from 18 to $74 \%$ ( $p \leq .0001)$, respectively. Behavior: The number of babies being suctioned and/or ventilated at birth did not change from pre to post, and the use of stimulation in the delivery room decreased after HBB training. 
TABLE 2. Simulation Training With HBB $(n=6)$ and Other Methodologies $(n=3)$ (Continued)

\begin{tabular}{|c|c|}
\hline CITATION & STUDY DESIGN \\
\hline $\begin{array}{l}\text { Msemo et al. } \\
\text { (2013) }\end{array}$ & $\begin{array}{l}\text { Prospective intervention } \\
\text { study, with one group pre- } \\
\text { and post-, to determine if } \\
\text { implementation of the } \\
\text { HBB program would } \\
\text { reduce neonatal mortality } \\
\text { on day } 1 \text { (within } 24 \text { hours } \\
\text { of birth) by } 50 \% \text { and } \\
\text { reduce by } 25 \% \text { the rates of } \\
\text { FSBs. }\end{array}$ \\
\hline $\begin{array}{l}\text { Seto et al. } \\
(2015)\end{array}$ & $\begin{array}{l}\text { Prospective intervention } \\
\text { study with one group pre- } \\
\text { and post-, to assess the } \\
\text { acquisition of knowledge } \\
\text { and skills following HBB } \\
\text { training; emphasis on the } \\
\text { "Golden Minute" } \\
\text { following birth. }\end{array}$ \\
\hline
\end{tabular}

Bang et al. Prospective intervention (2016)

Bellad et al. (2016)

\section{PARTICIPANTS}

Data collected on birth outcomes in eight pilot hospitals over 2 months prior to HBB training in September 2009;

post-intervention data

collection was initiated after the initial training of providers in each hospital until March 2012. Pre ( $n=8,124$ births) and post ( $n=78,500$ births) Setting: Tanzania

\section{Nurses, MDs}

$n=70$ (39 nurses, 31 MDs)

Setting: Honduras, Hospital Enrique Aguilar Cerrato

\section{INTERVENTION}

Two-day training of 40 master trainers from eight pilot hospitals, then a 1-day training of HWs (primarily midwives) at each hospital progressively over a 9-month period. A simulator was placed in the labor and delivery suite where every provider documented basic skills including FMV before starting a shift.

One-day, 8-hour workshop using the Spanish HBB translation and action plan, newborn simulators, and bag-mask ventilation.
Midwives, nurses, MDs trained $(n=2,227)$ across 71 facilities and 52 geographical clusters $n=2,227$ in initial training; $n=835$ in refresher training Setting: Nagpur and Belgaum, India, and Eldoret, Kenya, facilities in the NICHD Global Network research sites

(Same as above) $n=70,704$ births > $1,500 \mathrm{~g}$ in 52 clusters $(35,000+$ pre and $35,000+$ post $)(46 \%$ of registry births in the 71 sites)

Setting: Kenya and India (same as above)
Three-day HBB trainings Daily bag and FMV practice, equipment checks, and supportive supervision post-training emphasized.
HBB training (as above) and monitoring to selected facilities included training, direct supervision, accountability measures for delivery room record-keeping, bag and mask ventilation practice, resuscitation debriefings, death audits, site visits, etc.

\section{KEY FINDINGS}

Behavior: Use of stimulation increased from $47 \%$ to $88 \%$ (RR 1.87; 95\% Cl 1.82-1.90; $p<.0001)$ and suctioning from $15 \%$ to $22 \%$ (RR 1.40; 95\% Cl 1.33-1.46; $P<$ .0001).

Results: Implementation associated with a sustained $47 \%$ reduction in 24 -hour neonatal mortality and a $24 \%$ reduction in FSB after 2 years.

Knowledge and Skills: Statistically significant improvements in posttest scores for MCQs, bag-mask ventilation, and OSCE B. Achievement of ventilation by the "Golden Minute" improved from $27.9 \%$ pre-test to $42.4 \%$ posttest $(p=.02)$.

Knowledge and Skills: Knowledge test pass scores improved from $74 \%$ to $99 \%$ $(p<.001)$ post-initial training. Ventilation training pass scores improved from only $5 \%$ to $97 \%$ post-initial training $(p<.0001)$. During pre-refresher training evaluation, $99 \%$ passed the knowledge test, but pass rates for OSCE B fell from 99\% (post-initial training) to $81 \%$.

Results: HBB training of facility birth attendants was not associated with significant population reductions in perinatal mortality, stillbirth, or neonatal mortality among all neonates $\geq 1,500$ g; however, in the Kenyan facilities, the PMR and FSR decreased. The pre-post changes in mortality in the HBB-trained facilities in India were not significant. 
TABLE 2. Simulation Training With HBB $(n=6)$ and Other Methodologies $(n=3)$ (Continued)

\begin{tabular}{|c|c|}
\hline CITATION & STUDY DESIGN \\
\hline $\begin{array}{l}\text { Eblovi et al. } \\
\text { (2017) }\end{array}$ & $\begin{array}{l}\text { Prospective intervention } \\
\text { study, with one group } \\
\text { post-intervention only at } \\
\text { three points in time, to } \\
\text { determine the impact of } \\
\text { HBB trainings provided to } \\
\text { rural Ghanaian midwives } \\
\text { on their skill retention. } \\
\text { They also had midwives } \\
\text { record births post-training } \\
\text { in logbooks, to examine } \\
\text { first } 24 \text {-hour mortality of } \\
\text { the newborns they served } \\
\text { for a year. }\end{array}$ \\
\hline
\end{tabular}

Vail et al. (2017)

PARTICIPANTS
Midwives $n=48$ Setting:
Ghana, rural health clinics

\section{INTERVENTION}

AAP trained Master

Trainers provided two

2- day HBB trainings

( $n=24$ participants each)

and 2-day refresher courses one year later; initial sessions including introduction of the material, discussion, hands-on instruction, and repetitive practice of $\mathrm{NR}$ techniques using NeoNatalie mannequins with various clinical scenarios.

Nurses and midwives at 80 primary health facilities: $89 \%$ auxiliary nurses and midwives, $11 \%$ general nurses and midwives. $n=658$ Setting: Bihar, India
Training 1 week per month for 8 months implemented by trained nurse mentors. (Skills evaluated by clinical complexity of the simulated scenario, which ranged from level 1, requiring NR without maternal complications, to level 3, requiring simultaneous management of neonatal and maternal complications. Simulations were videorecorded and coded for predefined clinical skills using "Studiocode")

\section{KEY FINDINGS}

Skills: OSCE scores decreased from immediately after training (94.9\%) to 4 months later $(81.2 \%$, $p<.001)$. Four months following refresher course, scores improved to same level attained initially (92.7\%, $p=.001)$.

Behavior: $5.0 \%$ of newborns required $\mathrm{FMV}$; percentage consistent with global estimates.

Results: $0.71 \%$ neonates died, compared with a national first 24-hour mortality estimate of $1.7 \%$.

Skills: 298 videos requiring NR simulation were analyzed; as simulation complexity increased, percentage simulations in which nurses completed key steps of NR did not change, suggesting that they were able to maintain key skills despite higher clinical demands. As simulation complexity increased from level 1 to 3 , time to completion of key NR steps decreased nonsignificantly. care of the mother-infant dyad.
NR skills of nurses in Bihar, as part of PRONTO focus on simultaneous
design - one group points in time (weeks 3, 5, and 7) to assess the
impact of an in situ simulation training program (PRONTO) on

Note. $\mathrm{NR}=$ neonatal resuscitation; FMV = face-mask ventilation; $\mathrm{HBB}=$ Helping Babies Breathe; $\mathrm{MCQ}=$ multiple-choice test question; OSCE = Objective Structured Clinical Evaluation; FSB = fresh stillbirth; FSR = fresh stillbirth rates; ENM = early neonatal mortality; PMR = perinatal mortality rate; ENC = Essential Newborn Care course; AAP = American Academy of Pediatrics; NRP = Neonatal Resuscitation Program; RCT = randomized controlled trial; $\mathrm{WHO}=$ World Health Organization; $\mathrm{HW}=$ health worker; $\mathrm{CI}=$ confidence interval; $\mathrm{RR}=$ relative risk; $\mathrm{MD}=$ medical doctor; $\mathrm{TBAs}=$ traditional birth attendants; LMIC = low- and middle-income country; NICHD = National Institute of Child Health and Human Development; PRONTO = Programa de Rescate Obstétrico y Neonatal: Tratamiento Óptimo y Oportuno.

aThe "Golden Minute" is a term to denote the critical first minute after birth during which neonates should begin breathing spontaneously or receive assistance with adequate and effective bag-mask ventilation.

The studies are presented by category of teachinglearning approach:

\section{Simulation training with HBB $(n=6)$ and related training programs $(n=3)$ (Table 2).}

Duration of training based on HBB and other training programs ranged from 1 to 5 days. Over 3,000 health workers, mostly nurses and midwives, were trained across the nine studies in different aspects of basic newborn care and neonatal resuscitation.
All nine studies utilized low-cost and low-tech simulation technology with birthing simulator mannequins specifically designed for neonatal resuscitation demonstrations and evaluations.

Subbiah et al. (2012) reported on training nurses in India on routine neonatal care and neonatal resuscitation using modules and hands-on skill-building sessions developed by the National Neonatology Forum, India, and found an increase in knowledge and skills among training participants. In contrast, Goudar et al. (2012) reported the results of a prospective 
TABLE 3. eLearning Interventions $(n=3)$

\begin{tabular}{|c|c|}
\hline CITATION & STUDY DESIGN \\
\hline $\begin{array}{l}\text { Thukral et al. } \\
\text { (2012) }\end{array}$ & $\begin{array}{l}\text { Prospective intervention } \\
\text { study with one group pre an } \\
\text { post, to evaluate the efficacy } \\
\text { of Internet-based distance } \\
\text { learning in conjunction } \\
\text { with local hands-on skill } \\
\text { enhancement in improving } \\
\text { knowledge and skills of } \\
\text { essential newborn care } \\
\text { among in-service nursing } \\
\text { health professionals. }\end{array}$ \\
\hline
\end{tabular}

Prakash et al. Prospective intervention (2016) study with one group pre and post, to evaluate the efficacy of a point of care android phone based-app"All India Institute of Medical Sciences (AIIMS)-WHO Collaborating Centre Standard Treatment Protocols " on the knowledge and skill scores, and satisfaction among SNCU physicians managing sick neonates.

Lund et al. (2016)

\section{PARTICIPANTS}

Nurses from seven

health facilities

$(n=98)$

Setting: India and

Maldives

\section{Pediatricians}

$(n=32)$

Setting: Tamil Nadu, India

Cluster-RCT with the facility
as the unit of randomization,
to determine the effects of
the SDA on perinatal survival
and on HW knowledge and
skills in NR. The SDA is a free
training tool in emergency
obstetric and neonatal care
that uses visual guidance in
animated videos with
clinical instructions for
management.

Women in active

labor $(n=3,601)$ were included at admission and followed until 7 days after delivery to record perinatal mortality. HWs trained $(n=176)$ $n=70$ healthcare facilities:

35 intervention/35

control

Setting: Ethiopia (five rural districts)

\section{INTERVENTION}

Delivery of course material over 5 weeks (two lessons per week), moderated by online tutors. Participants managed case scenarios, and participated in discussion forums/ synchronous chat sessions. Local tutors at the partnering health facilities administered skill learning

The training of participants on four modules: (a) hypothermia, (b) seizures, (c) shock, and (d) feeding of the low birthweight baby, was covered in a 1-day workshop, with presentation of the algorithmic management of the respective clinical conditions on the "app," followed by interactive discussions and group video viewing with skill demonstrations.

HWs in intervention facilities received a smartphone with the SDA and a 1-day introduction to use of the smartphone/SDA with group video viewing. At control facilities, the HWs provided standard care without the assistance of the SDA.

\section{KEY FINDINGS}

Reaction: $79 \%$ completed the evaluation and $100 \%$ of respondents expressed satisfaction.

Knowledge and Skills: There was a significant increase in knowledge and skills scores: MCQ test: mean difference: 6.4 (95\% Cl: 5.6-7.17, $p<$ $.001)$, OSCE: mean difference: 15.4 (95\% Cl: 12.7-18.1, $p<$ .001).

Reaction: The median satisfaction score with the course was 4 (out of 5) (Likert's scale). Focus group discussions revealed that participants were satisfied with the training methods.

Knowledge and Skills: Improvement from pre to post-training on mean knowledge scores (mean difference 8.7 out of 25 [95\% $\mathrm{Cl} 7.6$ to 9.9$]$ ), and the composite mean skill scores (mean difference 13.2 out of 75 [95\% Cl 10.4 to 15.9$]$ )

Knowledge and Skills:

Knowledge change corresponded to $39 \%$ and $38 \%$, respectively at 6 and 12 months, above the control level. Skill change corresponded to $80 \%$ and $107 \%$, respectively, above controls.

Results: Use of the SDA was associated with a non-significant lower perinatal mortality of 14 per 1,000 births in intervention clusters compared with 23 per 1,000 births in control clusters (odds ratio, $0.76 ; 95 \% \mathrm{Cl}$, $0.32-1.81)$.

Note. $\mathrm{MCQ}=$ multiple-choice test question; $\mathrm{OSCE}=$ objective structured clinical evaluation; $\mathrm{CI}=$ confidence interval; $\mathrm{SNCU}=$ special newborn care unit; $\mathrm{SDA}=$ Safe Delivery App; HW = health worker; $\mathrm{RCT}=$ randomized controlled trial; $\mathrm{WHO}=$ World Health Organization.

community-based RCT in rural India after training birth attendants (nurses, physicians, auxiliary nurse midwives, and others) using WHO's Essential Newborn Care (ENC or ENCC) Course (WHO, 2010) and the AAP's Neonatal Resuscitation Program (NRP) (AAP, n.d.-b) They found a significant decrease in perinatal mortality in both home and facility births after provider ENC training. ${ }^{3}$ Randomization to NRP or refresher ENC training was done after the initial ENC training, but no further reduction in mortality was noted in NRP-designated communities.

Implementation of HBB training ${ }^{4}$ in select rural Tanzanian hospitals was reported in two studies included in this review. Ersdal et al. (2013) reported 
on data collected 7 months after HBB training in one hospital. They found significantly increased skill scores for both routine newborn care and neonatal resuscitation compared with pre-training scores. However, in terms of provider behavior, neonatal management in the delivery room during the corresponding time period did not improve; the number of babies being suctioned and/or ventilated at birth did not change from pre- to post-training, and the use of stimulation in the delivery room paradoxically decreased after HBB training. Msemo et al's (2013) study in eight facilities in Tanzania (including the one facility reported on by Ersdal et al.), reported that in the 2 years after HBB training, the frequency of stimulation and suctioning increased overall in the eight hospitals; additionally, there was an associated sustained $47 \%$ reduction in neonatal mortality within 24 hours of birth and a $24 \%$ reduction in fresh stillbirths.

Seto et al. (2015) tested the effect of HBB training in one hospital in Honduras and reported that participants demonstrated statistically significant improvements in posttest scores for a multiplechoice questionnaire, bag-mask ventilation skills, and "Objective Structured Clinical Evaluation-B" (for a complex resuscitation scenario). However, although participants achieved high scores on the knowledge test, they improved from $27.9 \%$ on the pre-test to only $42.4 \%$ on the posttest $(p=.02$ ) for ventilation by the "Golden Minute." The "Golden Minute" is a term to denote the critical first minute after birth during which neonates should begin breathing spontaneously or receive assistance with adequate and effective bag-mask ventilation.

Research on the impact of HBB trainings conducted in 71 facilities in the National Institute of Child Health and Human Development Global Network research sites in India and Kenya found immediate post-training results for knowledge and skills to be significantly higher than at pre-training. However, while knowledge scores remained high (at 99\%) at 6-7 months post-training, skill scores dropped by $20 \%$ on average (Bang et al., 2016). It is noteworthy that initial skill scores were only 5 on average out of 100 (5\%) for 2,227 birth attendants including nurses, midwives, and medical doctors; thus, the starting point was low in terms of provider competence. Bellad et al. (2016) did an analysis of registered births in the local population before and after HBB training in the same geographic clusters tested in Bang et al. (2016). In this study, however, the researchers examined all births registered in the local population in the study areas, including non-facility births. Training was not associated with significant reductions in perinatal mortality, stillbirth, or neonatal mortality in the population. Similar to Bang et al. (2016), Eblovi et al. (2017) found that immediate post-HBB training skill scores waned when tested after 4 months, but scores rebounded to post-initial training levels after a refresher training.

Vail et al. (2017) reported on an in situ simulation training in Bihar, India, implemented primarily with auxiliary nurses and midwives from 80 primary care facilities 1 week per month over an 8-month period using the PRONTO ("Programa de Rescate Obstétrico y Neonatal: Tratamiento Óptimo y Oportuno") Program (Pronto International, n.d.). The focus of the PRONTO training is on teaching providers to simultaneously manage maternal and neonatal complications rather than focusing on neonatal resuscitation skills in isolation. Training sessions are conducted in resource-limited facilities where providers actually work, rather than in classrooms. The researchers videorecorded providers' neonatal resuscitation simulations and coded for predefined clinical skills, with increasing clinical complexity of the simulated scenario (from the simplest scenarios requiring only neonatal resuscitation to complex situations requiring simultaneous management of neonatal and maternal complications; Vail et al., 2017). The researchers measured time to completion of key steps in the resuscitation algorithm as complexity increased. They found that as complexity of simulations increased, the time elapsed between delivery and key resuscitation steps decreased, although not significantly.

2. eHealth / eLearning interventions $(\boldsymbol{n}=3)$ (Table 3). Studies focusing on eHealth/eLearning interventions for newborn health workers utilized the following approaches: (a) Internet-based distance learning in conjunction with local hands-on skill enhancement $(n=1)$ (Thukral et al., 2012) and (b) mLearning initiatives using mobile phones $(n=2)$ (Lund et al., 2016; Prakash et al., 2016).

Course modules on essential newborn care in Thukral et al. (2012) were delivered via distance learning using online material over 5 weeks to 98 nurses at seven health facilities in India and the Maldives. Participants managed case scenarios and participated in discussion forums and synchronous chat sessions moderated by local online tutors. Computer literacy was not considered an essential prerequisite for participants. Course content, based on WHO ENC 
materials, and evaluation methods had been field tested prior to the start of the study. Local tutors at the partnering health facilities administered skill learning in the final 2 weeks following the online course. Participants expressed favorable reactions to the training and scored significantly higher in knowledge and skills scores post-training as compared to pre-training. 22 participants were not computer literate prior to enrollment in the course, but did not experience difficulty; however, course delivery was limited to areas with an Internet connection.

eLearning initiatives using mobile phones or mobile electronic devices (mLearning) included a study by Prakash et al. (2016), who evaluated the efficacy of a training and point of care tool on the knowledge and skill scores among Special Newborn Care Unit doctors managing sick neonates in district hospitals. The tool was an android-based mobile phone application (App), entitled the "All India Institute of Medical Sciences-WHO Collaborating Centre Standard Treatment Protocols." The efficacy and acceptability of the App had been previously evaluated in India. Participants received a 1-day training on four modules related to key causes of neonatal mortality: hypothermia, seizures, shock, and nutrition for low birthweight babies. They were trained on how to access the treatment algorithms for these conditions on the App and on demonstration of skills by experienced facilitators. The App ran offline once downloaded, without the requirement of an Internet connection. Participants reported overall satisfaction with the training and found the App to be user friendly but noted that smartphone ownership may be a limiting factor for nursing staff. Mean knowledge and skill scores for participants differed significantly from pre- to post-training scores 3 weeks after introduction of the App.

A recent cluster-RCT tested the Safe Delivery App, a training and point of care tool for mobile phones and tablets. The Safe Delivery App aims to improve the management of basic obstetric and neonatal emergency care in low-income countries using visual guidance in animated videos with clinical instructions. The purpose of the trial by Lund et al. (2016) in Ethiopia was to determine the effects of training and use of the App on rural healthcare workers' knowledge and skills in neonatal resuscitation and on newborn perinatal survival. Smartphones were provided by the study, and the App was able to run completely offline once the content was downloaded.
Use of the Safe Delivery App was associated with statistically significant increases in knowledge and skill scores related to neonatal resuscitation at both 6 - and 12-months post-training and with a nonsignificant lower perinatal mortality in intervention clusters compared with control clusters.

\section{DISCUSSION}

The purpose of this scoping review was to explore what is known from the existing published research literature about technology-based newborn health learning initiatives for facility-based nurses and midwives in low- and middle-income countries. In this review, we identified a number of studies focusing on simulation training for facility-based health workers using evidence-based training programs such as ENC, NRP, HBB, and PRONTO. Additionally, we identified a limited number of studies utilizing eLearning initiatives, such as Internet-based online learning, and mobile phone mLearning applications. The content of the initiatives focused primarily on essential newborn care, including basic neonatal resuscitation and one study that tested an App targeting interventions for sick newborns (Prakash et al., 2016). Collectively, these interventions center around prevention and treatment of the major causes of neonatal deaths, particularly deaths in the intrapartum period and during the first week of life when intrapartum-related "birth asphyxia" takes a heavy toll. Evaluation study designs ranged from one-group pre-post intervention studies or one-group posttest only $(n=9)$, to more robust cluster RCTs $(n=2)$ (Goudar et al., 2012; Lund et al., 2016).

Results reported from simulation training programs (HBB, ENC, NRP, and PRONTO) in this review varied widely, both in terms of skill acquisition and retention, and in terms of provider behavior and patient outcomes. Some studies reported positive and negative results within the same study. The variable results suggest that while short simulation programs improve shortterm knowledge and skills and may improve longer-term practice in the simulated setting, the training may be insufficient to enable health workers to integrate and translate those skills into clinical practice. Results also suggest that performance decreases significantly over time and requires refresher training (Bang et al., 2016; Eblovi et al., 2017). These finding are consistent with other literature on the topic (Ersdal \& Singhal, 2013), which highlight the importance of programs targeting ongoing refresher training and local mentoring for skill 
retention in order to impact clinical management and patient outcomes and to increase sustainability. However, supervised practices for skill retention can be challenging and costly in resource-limited settings (Rule et al., 2017).

This review identified a dearth of studies focused on eLearning or other technology-based interventions, which points to the relative lack of peer-reviewed studies on eLearning and mLearning interventions for newborn health workers in low- and middle-income countries, which is consistent with findings reported elsewhere (Agarwal \& Labrique, 2014; Chandrasekaran et al., 2014). Thukral et al. (2012) demonstrated that online training is feasible and effective in increasing knowledge and skills and can be blended with local on-site skill learning in partnering institutions. Their findings suggest that this blended approach might be an economical and expeditious way to cover a wide geographical region with uniform standardized education. mHealth initiatives provided updated information to health workers through a training and point of care algorithm-based app for androids (Prakash et al., 2016) and through the Safe Delivery App, a learning resource for training providers on emergency obstetric and newborn care and for point of care use (Lund et al., 2016). Prakash et al. (2016) measured changes in doctors' knowledge and skill levels; Lund et al. (2016) measured changes and retention in birth attendants' knowledge and skill levels, demonstrating that the use of mobile phones is feasible for healthcare workers, irrespective of their educational level or prior training. Lund also found a nonsignificant lower perinatal mortality rate in intervention clusters compared with control clusters subsequent to Safe Delivery App use.

Simulation training is an increasingly utilized methodology for training healthcare providers to manage obstetrical and newborn emergencies such as birth asphyxia (Vail et al., 2017). Simulation-based initiatives in this review primarily used mannequin-based simulation, which has grown in healthcare education and training as a method of teaching, learning, and performance evaluation (Taekman et al., 2017). The advantages of simulation training are that it provides concrete learning opportunities within "realistic" and reproducible contexts (Fuchs, Miller, \& Berkowitz, 2009). Engaging providers to synthesize and apply knowledge and tasks according to a scenario, thereby promoting theoretical, cognitive, technical, and behavioral skills is another advantage of simulation training (Ersdal et al., 2013). Simulation is suitable for both pre- and in-service settings, with the potential to provide a continuum of training throughout a professional career (Nelissen et al., 2014). Additionally, simulation allows learners to practice new skills at their own pace, since scenarios can be slowed down to adapt to the needs of the learner. Scenarios can be used to train learners to prepare for emergency situations in settings where no patient will be harmed from the initial attempts of performing a procedure unfamiliar to the learner, and/or in situations that are too rare, serious, or expensive to recreate in real life (Stitely, Cerbone, Nixon, \& Bringman, 2011). The disadvantages of simulation training are that it can be costly and requires specific equipment, learners to be physically present, and capable trainers, which may not be a practical option for reaching health workers in the most remote settings.

Learning opportunities are harder to access for clinicians working in rural and remote areas, adding to challenges for remote and rural clinicians that already include professional isolation, inadequate communication with peers in the cities, and a lack of appropriate equipment and technologies that hinder timely and appropriate quality obstetric and neonatal care (Ellard et al., 2016).

mHealth and mLearning, have been linked to expanding mobile phone penetration in lowand middle-income countries. Mobile Learning (M-Learning) provides important opportunities for the delivery of health information and services to remote locations, expanding access by remote health workers to current evidence-based information in order to improve clinical decision-making and management of patients (Agarwal \& Labrique, 2014; Obasola, Mabawonku, \& Lagunju, 2015). Evidence from systematic reviews and other studies suggest that mHealth initiatives can contribute to improving maternal and newborn health in a variety of ways, for example, mHealth interventions can help by directing health prevention information to women, community workers, and the public, expediting referrals for management of obstetric and newborn health emergencies, monitoring patient adherence to treatment regimens, and conducting surveillance (Amoakoh-Coleman et al., 2016; Lee et al., 2016; Lund et al., 2014; Obasola et al., 2015). Advantages of mHealth initiatives are many, including reduced program cost, practicality in contexts where there are insufficient numbers of available instructors to provide quality training (Thukral et al., 2012), and ease of collaboration with individuals in remote locations at flexible times. Apps are also easy to share and can be updated easily as clinical practice guidelines evolve 
(Prakash et al., 2016). An additional benefit of mLearning and online learning is the opportunity for providers to participate in self-paced learning with standardized course delivery and monitoring, allowing the learner to tailor their own learning objectives and giving the learner control over content and pace of learning. The findings from Lund et al. (2016) support those of other studies that providers perceive the use of mobile tools as a promising opportunity for healthcare workers' self-improvement with effects on their motivation, selfefficacy, and enthusiasm, in contrast to passive learning models (Chandrasekaran et al., 2014; Labrique, Vasudevan, Kochi, Fabricant, \& Mehl, 2013). Disadvantages of eLearning programs include lack of face-to-face interaction, poor Internet connectivity in certain regions, non-user-friendly interfaces, and digital illiteracy (Chandrasekaran et al., 2014).

The feasibility of mLearning has largely advanced beyond earlier barriers of bandwidth and the cost of Internet access (Obasola et al., 2015). However, despite the rapid growth of mHealth and eHealth programs, research and evidence on their effectiveness are scarce (Agarwal, Perry, Long, \& Labrique, 2015; Batavia \& Kaonga, 2014; Sondaal et al., 2016; Tomlinson, Swartz, Rotheram-Borus, \& Tsai, 2013). More specifically, there is a lack of trials of mobile phone and other eHealth interventions in low- and middle-income countries that have health outcomes, or level-4 Kirkpatrick findings, as a primary outcome (Lund et al., 2016; Obasola et al., 2015). One review hypothesized that the lack of evidence related to mHealth may be because organizations piloting mHealth projects in the field are perhaps more focused on implementation of mHealth programs, and are opting to publish open-source gray literature and white papers rather than publishing in peer-reviewed papers (Batavia \& Kaonga, 2014). Other challenges to overcome include a lack of standardization of eLearning evaluation methods (Chandrasekaran et al., 2014), using validated and reliable measurement instruments.

Our identification of studies in this review was limited by the selected databases and search terms that we used, which may have resulted in relevant studies being missed from other databases or from the use of associated search terms. Additionally, we were limited to analysis of results reported in the selected studies, which made comparisons between learning interventions difficult due to lack of comparable data. Future research on simulation training and eHealth/mHealth should emphasize use of robust study designs, using valid and reliable measurement instruments, and measuring higher-level outcomes (Kirkpatrick levels 3 and 4) such as behavior change and patient results (Ameh \& van den Broek, 2015; Amoakoh-Coleman et al., 2016, Chandrasekaran et al., 2014). Feasibility studies in remote areas are needed to determine if certain technology-enhanced approaches are viable for the specific context or country, as well as cost analyses, to identify potentially scalable approaches leading to better coverage of skilled birth attendants to enhance proficiency in essential newborn care and neonatal resuscitation.

\section{CONCLUSION}

Given the high costs and logistical challenges of inperson training programs in low-income settings, the healthcare workers who most need support are often the least likely to receive it. Studies examined here propose innovative technology-based learning initiatives to address gaps in resource-poor locations. Learning approaches that emphasize simulation training and eHealth approaches for maternal and newborn health workers hold promise for identifying potentially scalable approaches toward establishing better coverage of skilled birth attendants with proficiency in essential newborn care and neonatal resuscitation. This is especially critical for health workers in more remote areas, where maternal and newborn mortality are the highest. However, existing simulation literature demonstrates that translation of knowledge gained during simulation into improved clinical outcomes in real births is difficult and variable. The volume of evidence demonstrating the potential benefit of mHealth strategies, especially in the neonatal period, is limited. Learning initiatives with high priority content and demonstrated effectiveness should be tested using rigorous research methods to determine long-term effectiveness and to measure cost-effectiveness in different contexts and priority areas. However, mHealth and blended learning initiatives combining distance learning and simulation training hold many advantages. Future research is suggested documenting patient outcomes due to technology-based learning interventions, in order to enhance the quality of care of nurses and midwives in maternal and newborn health.

\section{NOTES}

1. These estimates are somewhat uncertain due to a paucity of data from low- and middle-income countries and a lack of reliable vital registration systems from settings where mortality is highest. In addition, intrapartum-related deaths are likely underreported or misclassified as fresh stillbirths (Ersdal \& Singhal, 2013). 
2. Intrapartum-related "birth asphyxia" is presumed to cause approximately $25 \%$ of neonatal deaths (Ersdal \& Singhal, 2013).

3. Essential Newborn Care includes evidence-based guidelines for routine care and initial management of neonates following birth and during the first week after birth, including routine neonatal care, initiation of breathing and resuscitation, thermoregulation, early and exclusive breastfeeding, skin-to-skin care, care of the small baby, counseling on baby care and danger signs, and recognition and initial management of complications.

4. Helping Babies Breathe, launched in 2010 by the AAP, in collaboration with WHO and other global partners, is an evidence-based curriculum in basic neonatal care and resuscitation, utilizing simulation-based training, to educate large numbers of birth attendants in low- and middle-income countries in order to reduce global neonatal mortality (Ersdal et al., 2013; Singhal et al., 2012). ENC and NRP were incorporated into the training program that became $\mathrm{HBB}$, although both are still being used. HBB is centered on basic care for all babies (warmth, drying, stimulation, and suctioning) and ventilation within the important "Golden Minute" of life (Rule et al., 2017). HBB promotes active learning using hands-on skills practice using the "NeoNatalie" newborn simulator and through paired learning, self-reflection, and group discussion. Immediately following the training, learners are tested with four formative assessments to determine learner competence and performance: a multiple-choice questionnaire, a bag-mask ventilation skills checklist, and two validated simulation evaluation tools called "OSCEs." The educational kit includes an action plan, a culturally adopted flip-over facilitator guide, and a student workbook; course material is largely pictorial with simple text. Though aimed at midwives, the curriculum can also be adapted for health workers with limited literacy. Supplemental oxygen, intubation, chest compressions, and medications do not enter the algorithm since these actions are not relevant for most of the babies requiring assistance (Ersdal \& Singhal, 2013). Recently, HBB has been updated and incorporated into a suite of evidence-based training programs, "Helping Babies Survive," which includes the HBB 2nd edition, "Essential Care for Every Baby" and "Essential Care for Small Babies" to address the other leading causes of newborn death (http://globalhealth.org/helpingbabies-survive/).

\section{REFERENCES}

Agarwal, S., \& Labrique, A. (2014). Newborn health on the line: The potential mHealth applications. JAMA, 312(3), 229230. doi:10.1001/jama.2014.6371

Agarwal, S., Perry, H. B., Long, L. A., \& Labrique, A. (2015). Evidence on feasibility and effective use of $\mathrm{mHealth}$ strategies by frontline health workers in developing countries: Systematic review. Tropical Medicine \& International Health, 20(8), 1003-1014. doi:10.1111/ tmi. 12525

Ameh, C. A., \& van den Broek, N. (2015). Making it happen: Training health-care providers in emergency obstetric and newborn care. Best Practice and Research:
Clinical Obstetrics and Gynaecology, 29(8), 1077-1091. doi:10.1016/j.bpobgyn.2015.03.019

American Academy of Pediatrics. (n.d.-a). Helping babies breathe. Retrieved from https://www.aap.org/en-us/ advocacy-and-policy/aap-health-initiatives/helpingbabies-survive/Pages/Helping-Babies-Breathe.aspx

American Academy of Pediatrics. (n.d.-b). Neonatal resuscitation program. Retrieved from https://www.aap.org/enus/continuing-medical-education/life-support/NRP/ Pages/NRP.aspx

Amoakoh-Coleman, M., Borgstein, A. B., Sondaal, S. F., Grobbee, D. E., Miltenburg, A. S., Verwijs, M., . . . Klipstein-Grobusch, K. (2016). Effectiveness of mHealth interventions targeting health care workers to improve pregnancy outcomes in low- and middle-income countries: A systematic review. Journal of Medical Internet Research, 18(8), e226. doi:10.2196/jmir.5533

Amoakoh, H. B., Klipstein-Grobusch, K., Amoakoh-Coleman, M., Agyepong, I. A., Kayode, G. A., Sarpong, C., . . . Ansah, E. K. (2017). The effect of a clinical decisionmaking mHealth support system on maternal and neonatal mortality and morbidity in Ghana: Study protocol for a cluster randomized controlled trial. Trials [E], 18(1), 1-11. doi:10.1186/s13063-017-1897-4

Arksey, H., \& O’Malley, L. (2005). Scoping studies: Towards a methodological framework. International Journal of Social Research Methodology, 8(1), 19-32. doi:10.1080/ 1364557032000119616

Bang, A., Patel, A., Bellad, R., Gisore, P., Goudar, S. S., Esamai, F., . . . Hibberd, P. L. (2016). Helping Babies Breathe (HBB) training: What happens to knowledge and skills over time? BMC Pregnancy and Childbirth, 16(1), 364. doi:10.1186/s12884-016-1141-3

Batavia, H., \& Kaonga, N. (2014). mHealth support tools for improving the performance of frontline health workers: An inventory and analytical review. Retrieved from http://lifesavingcommodities.org/wpcontent/uploads/2015/05/mhealth_fhw_inventory.pdf

Bell, S., Rominski, S., Bam, V., Donkor, E., \& Lori, J. (2013). Analysis of nursing education in Ghana: Priorities for scaling-up the nursing workforce. Nursing and Health Sciences, 15, 244-249. doi:10.1111/nhs.12026

Bellad, R. M., Bang, A., Carlo, W. A., McClure, E. M., Meleth, S., Goco, N., . . . Group, H. B. B. S. (2016). A prepost study of a multi-country scale up of resuscitation training of facility birth attendants: Does Helping BabiesBreathe training save lives? BMC Pregnancy and Childbirth, 16(1), 222. doi:10.1186/s12884-016-0997-6

Chandrasekaran, A., Thukral, A., \& Deorari, A. K. (2014). E-learning in newborn health - A paradigm shift for continuing professional development for doctors and 
nurses. Indian Journal of Pediatrics, 81(12), 1376-1380. doi:10.1007/s12098-014-1362-2

Eblovi, D., Kelly, P., Afua, G., Agyapong, S., Dante, S., \& Pellerite, M. (2017). Retention and use of newborn resuscitation skills following a series of helping babies breathe trainings for midwives in rural Ghana. Global Health Action, 10(1), 1387985. doi:10.1080/16549716. 2017.1387985

Ellard, D. R., Shemdoe, A., Mazuguni, F., Mbaruku, G., Davies, D., Kihaile, P., . . . O’Hare, J. P. (2016). Can training non-physician clinicians/ associate clinicians (NPCs/ACs) in emergency obstetric, neonatal care and clinical leadership make a difference to practice and help towards reductions in maternal and neonatal mortality in rural Tanzania? The ETATMBA project. BMJ, 6(2), e008999. doi:10.1136/bmjopen-2015-008999

Ersdal, H. L., \& Singhal, N. (2013). Resuscitation in resource-limited settings. Seminars in Fetal and Neonatal Medicine, 18(6), 373-378. doi:10.1016/j.siny. 2013.07.001

Ersdal, H., Vossius, C., Bayo, E., Mduma, E., Perlman, J., Lippert, A., \& Søreide, E. (2013). A one-day "Helping Babies Breathe" course improves simulated performance but not clinical management of neonates. Resuscitation, 84(10), 1422-1427. doi:10.1016/j.resuscitation. 2013.04.005

Fuchs, K. M., Miller, R. S., \& Berkowitz, R. L. (2009). Optimizing outcomes through protocols, multidisciplinary drills, and simulation. Seminars in Perinatology, 33(2), 104-108. doi:10.1053/j.semperi.2008.12.002

Goudar, S. S., Dhaded, S. M., Patil, V. D., Mahantshetti, N. S., Bellad, R. M., Kodkany, B., . . Carlo, W. A. (2012). ENC training reduces perinatal mortality in Karnataka, India. Journal of Maternal-Fetal and Neonatal Medicine, 25(6), 568-574. doi:10.3109/14767058.2011.584088

Hudspeth, J., Curry, C. L., Sacks, Z., \& Surena, C. (2015). Continuing professional development in low-resource settings: Haiti as example. Annals Global Health, 81(2), 255-259. doi:10.1016/j.aogh.2015.03.004

Kirkpatrick, D. (1996). Great ideas revisited. Training and Development, 50(1), 54-59.

Klunklin, A., Viseskul, N., Sripusanapan, A., \& Turale, S. (2010). Readiness for self-directed learning among nursing students in Thailand. Nursing and Health Sciences, 12(2), 177-181. doi:10.1111/j.1442-2018.2010.00515.x

Labrique, A. B., Vasudevan, L., Kochi, E., Fabricant, R., \& Mehl, G. (2013). mHealth innovations as health system strengthening tools: 12 common applications and a visual framework. Global Health, Science and Practice, 1(2), 160-171. doi:10.9745/GHSP-D-13-00031

Lawn, J., Bhutta, Z., Wall, S., Peterson, S., Daviaud, E. (2017). Cadres, content and costs for community-based care for mothers and newborns from seven countries: implications for universal health coverage. Health Policy and Planning, 32, 2017, i1-i5 doi:10.1093/heapol/czx104

Lawn, J. E., Kinney, M., Lee, A., Chopra, M., Donnay, F., Paul, V., . . . Darmstadt, G. (2009). Reducing intrapartumrelated deaths and disability: Can the health system deliver? International Journal of Gynecology and Obstetrics, 107, S123-S142. doi:10.1016/j.ijgo.2009.07.021

Lawn, J. E., Lee, A. C., Kinney, M., Sibley, L., Carlo, W. A., Paul, V. K., . . D Darmstadt, G. L. (2009). Two million intrapartum-related stillbirths and neonatal deaths: Where, why, and what can be done? International Journal of Gynaecology and Obstetrics: The Official Organ of the International Federation of Gynaecology and Obstetrics, 107(Suppl. 1), S5. doi:10.1016/j.ijgo.2009.07.016

Lee, S., Nurmatov, U., Nwaru, B., Mukherjee, M., Grant, L., \& Pagliari, C. (2016, June 1). Effectiveness of mHealth interventions for maternal, newborn and child health in low- and middle-income countries: Systematic review and meta-analysis. Journal of Global Health, 6(1), 010401. doi:10.7189/jogh.06.010401

Lund, S., Boas, I. M., Bedesa, T., Fekede, W., Nielsen, H. S., \& Sorensen, B. L. (2016). Association between the safe delivery app and quality of care and perinatal survival in Ethiopia: A randomized clinical trial. JAMA Pediatrics, 170(8), 765-771. doi:10.1001/jamapediatrics.2016.0687

Lund, S., Rasch, V., Hemed, M., Boas, I. M., Said, A., Said, K., . . . Nielsen, B. B. (2014). Mobile phone intervention reduces perinatal mortality in Zanzibar: Secondary outcomes of a cluster randomized controlled trial. JMIR mHealth and uHealth, 2(1), e15. doi:10.2196/mhealth.2941

Marchant, T., Tilley-Gyado, R. D., Tessema, T., Singh, K., Gautham, M., Umar, N., ... Armstrong Schellenberg, J. (2015). Adding Content to Contacts: Measurement of High Quality Contacts for Maternal and Newborn Health in Ethiopia, North East Nigeria, and Uttar Pradesh, India. PLoS ONE 10(5), 1-19. doi:10.1371/ journal.pone.0126840

Msemo, G., Massawe, A., Mmbando, D., Rusibamayila, N., Manji, K., Kidanto, H., . . Perlman, J. (2013). Newborn mortality and fresh stillbirth rates in Tanzania after helping babies breathe training. Pediatrics, 131(2), X16. doi:10.1542/peds.2012-1795d

Nelissen, E., Ersdal, H., Ostergaard, D., Mduma, E., Broerse, J., Evjen-Olsen, B., . . . Stekelenburg, J. (2014). Helping mothers survive bleeding after birth: An evaluation of simulation-based training in a low-resource setting. Acta Obstetricia et Gynecologica Scandinavica, 93, 287-295. doi:10.1111/aogs.12321

Nilsson, C., Sorensen, B., \& Sorensen, J. (2014). Comparing hands-on and video training for postpartum 
hemorrhage management. Acta Obstetricia et Gynecologica Scandinavica, 93(5), 517-520. doi:10.1111/ aogs. 12372

Obasola, O., Mabawonku, I., \& Lagunju, I. (2015). A review of e-Health interventions for maternal and child health in sub-Sahara Africa. Maternal \& Child Health Journal, 19(8), 1813-1824. doi:10.1007/s10995-015-1695-0

Prakash, V., Thukral, A., Sankar, M. J., Agarwal, R. K., Paul, V. K., \& Deorari, A. K. (2016). Efficacy and acceptability of an "App on sick newborn care" in physicians from newborn units. BMC Medical Education. Advance online publication. doi: 10.1186/s12909-016-0579-3 16(1).

Pronto International. (n.d.). Pronto training programs. Retrieved from http://prontointernational.org/prontotraining-programs/

Rule, A. R., Maina, E., Cheruiyot, D., Mueri, P., Simmons, J. M., \& Kamath-Rayne, B. D. (2017). Using quality improvement to decrease birth asphyxia rates after 'Helping Babies Breathe' training in Kenya. Acta Paediatrica (Oslo, Norway: 1992), 106(10), 1666-1673. doi:10.1111/apa.13940

Seto, T. L., Tabangin, M. E., Josyula, S., Taylor, K. K., Vasquez, J. C., \& Kamath-Rayne, B. D. (2015). Educational outcomes of helping babies breathe training at a community hospital in Honduras. Perspectives on Medical Education, 4(5), 225-232. doi:10.1007/s40037-015-0214-8

Singhal, N., Lockyer, J., Fidler, H., Keenan, W., Little, G., Bucher, S., . . . Niermeyer, S. (2012). Helping babies breathe: Global neonatal resuscitation program development and formative educational evaluation. Resuscitation, 83(1), 90-96. doi:10.1016/ j.resuscitation.2011.07.010

Sondaal, S. F., Browne, J. L., Amoakoh-Coleman, M., Borgstein, A., Miltenburg, A. S., Verwijs, M., \& KlipsteinGrobusch, K. (2016). Assessing the effect of mHealth interventions in improving maternal and neonatal care in low- and middle-income countries: A systematic review. PLOS ONE, 11(5), 1-26, e0154664. doi:10.1371/ journal.pone. 0154664

Stitely, M., Cerbone, L., Nixon, A., \& Bringman, J. J. (2011). Assessment of a simulation training exercise to teach intrauterine tamponade for the treatment of postpartum hemorrhage. Journal of Midwifery and Women's Health, 56(5), 503-506.

Subbiah, N., Sarin, J., Jeeva, S., \& Geetanjali. (2012). Effectiveness of educational intervention on neonatal resuscitation among nursing personnel. Health and Population -Perspectives and Issues, 35(1), 36-45.

Taekman, J. M., Foureman, M. F., Bulamba, F., Steele, M., Comstock, E., Kintu, A., . . . Olufolabi, A. (2017). A novel multiplayer screen-based simulation experience for African learners improved confidence in management of postpartum hemorrhage. Front Public Health, 5, 248. doi:10.3389/fpubh.2017.00248

Thukral, A., Sasi, A., Chawla, D., Datta, P., Wahid, S., Rao, S., . . . Deorari, A. K. (2012). Online neonatal training and orientation programme in India (ONTOP-IN) The way forward for distance education in developing countries. Journal of Tropical Pediatrics, 58(6), 486-490. doi:10.1093/tropej/fms029

Tomlinson, M., Swartz, L., Rotheram-Borus, M. J., \& Tsai, A. C. (2013). Scaling up mHealth: Where is the evidence? PLOS Medicine, 10(2), e1001382. doi:10.1371/journal.pmed.1001382

Tuncalp, Ö., Were, W. M., MacLennan, C., Oladapo, O. T., Gulmezoglu, A. M., Bahl, R., ... Bustreo, F. (2015). Quality of care for pregnant women and newborns the WHO vision. BJOG, 122(8), 1045-1049.

United Nations Children's Fund, The Inter-agency Group for Child Mortality Estimation. (2017). Levels and trends in child mortality: Report 2017. Retrieved from https:// www.unicef.org/publications/files/Child_Mortality_ Report_2017.pdf

United Nations Children's Fund, The Inter-agency Group for Child Mortality Estimation. (2018). Levels and trends in child mortality: Report 2018. Retrieved from https:// www.unicef.org/publications/index_103264.html\#

Vail, B., Spindler, H., Morgan, M. C., Cohen, S. R., Christmas, A., Sah, P., . . Walker, D. M. (2017). Care of the mother-infant dyad: A novel approach to conducting and evaluating neonatal resuscitation simulation training in Bihar, India. BMC Pregnancy Childbirth, 17(1), 252. doi:10.1186/s12884-017-1434-1

Wall, S. N., Lee, A. C., Niermeyer, S., English, M., Keenan, W. J., Carlo, W., . . . Lawn, J. E. (2009). Neonatal resuscitation in low-resource settings: What, who, and how to overcome challenges to scale up? International Journal of Gynaecology and Obstetrics: The Official Organ of the International Federation of Gynaecology and Obstetrics, 107(Suppl. 1), S47-62, S63-44. doi:10.1016/j.ijgo.2009.07.013

World Health Organization. (1998). Basic newborn resuscitation: A practical guide. Retrieved from http://apps.who.int/iris/bitstream/ handle/10665/63953/WHO_RHT_MSM_98.1.pdf;jsess ionid=7CB5D83C6C94134E6AB5F2D77C6403C6? seq uence $=1$

World Health Organization. (2005). The world health report 2005: Make every mother and child count. Retrieved from http://www.who.int/whr/2005/whr2005_en.pdf

World Health Organization. (2006). The world health report 2006: Working together for health. Retrieved from http:// www.who.int/whr/2006/whr06_en.pdf 
World Health Organization. (2010). Essential newborn care course. Retrieved from http://www.who.int/maternal_ child_adolescent/documents/newborncare_course/en/

World Health Organization. (2011a). Strengthening nursing \& midwifery. WHA resolution 64.7. Retrieved from http://apps.who.int/gb/ebwha/pdf_files/WHA64/A64_ R7-en.pdf?ua $=1$

World Health Organization. (2011b). mHealth: New horizons for health through mobile technologies. Retrieved from http://www.who.int/goe/publications/ goe_mhealth_web.pdf

World Health Organization. (2017). WHO: Health throughout the life-course - February 2018 Update. [Video file]. Retrieved from https://youtu.be/w3q7Ujazrts

Disclosure. The authors have no relevant financial interest or affiliations with any commercial interests related to the subjects discussed within this article.
Acknowledgments. Lauren Bellhouse.

Correspondence regarding this article should be directed to Nancy Bolan, RN, CNM/FNP, MPH, PhD, Medical University of South Carolina, Charleston, SC. E-mail: nancy.e.bolan@gmail.com

Nancy E. Bolan, PhD, RN, CNM/FNP, MPH, Medical University of South Carolina, College of Nursing, Charleston, SC.

Susan D. Newman, PhD, RN, CRRN, Medical University of South Carolina, College of Nursing, Charleston, SC.

Lynne S. Nemeth, PhD, RN, FAAN, Medical University of South Carolina, College of Nursing, Charleston, SC. 